\title{
CLIMATE RESILIENCE INTERVENTIONS WITHIN GLOBAL CITIES: HOW ARE CITIES ADDRESSING CLIMATE HAZARDS AND WHAT'S MISSING?
}

\section{KEY MESSAGES}

- Global cities are at the forefront of the climate crisis with the global populated in urban areas located in areas of climate risk.

- Each city faces different climate risks and has taken different approaches to addressing climate risks from using new technologies, changing approaches to land use planning and policies to developing nature-based solutions and futureproofing infrastructure.

- The effective implementation adaptation interventions require overcoming many barriers such as strengthening governance, encouraging stakeholder engagement and improving climate risk data and metrics.

\section{INTRODUCTION}

As two thirds of the world's population shift to live in urban areas by 2050, cities are becoming increasingly important in the fight against climate change: cities can reduce carbon emissions, act as key sites to strengthen climate resilience, and protect citizens against dangerous climate hazards (Hunt and Watkiss 2011). As such, climate change is no longer solely about carbon emissions reduction; it is also about enabling cities to deal with the impact of climate change. To date, most studies on climate change focus on the development of mitigation strategies and have overlooked the increasing number of adaptation-related decisions and initiatives.

Cities are home to millions of people, yet many are located in areas of climate risk - such as on islands, on potential floodplains or on coastlines (more than $90 \%$ of urban areas are coastal) (Farhad et al. 2021). Infrastructure within these cities can worsen the impact of climate change, as the local built environment is often vulnerable to climate hazards. To prevent, or minimise, the damage these hazards can cause, cities are beginning to design and implement their own adaptation management strategies. These strategies aim to mitigate the impact on critical sectoral infrastructure and services, enhancing the well-being and prosperity of the communities they serve.

The focus on adaptation is important: climate hazards have potentially grave consequences for human health, livelihoods, and assets. This is most true for the urban poor, for people living in informal settlements, and other vulnerable groups. Often, lower income countries are the ones facing the brunt of climate hazards (despite causing, in general, lower carbon emissions), and their ability to respond to climate change impacts is hindered by factors such as a lack of resources.

Accelerating climate change in recent years has increased both the severity and the frequency with which some natural hazards occur, especially extreme weather events (e.g., flash flooding, heat waves and droughts). Climate impacts will increase further unless cities unite to limit global warming to 1.5 degrees as detailed in the 2015 Paris Agreement. To address this, cities must develop adaptation management strategies that can respond to the unavoidable impacts of climate change and become climate resilient by 2050 (see the European Union's Adaptation Strategy 2021 for examples).

\section{Authors:}

I Dr Katherine Maxwell, Associate, Visiting Fellow, Global Centre for Healthcare and Urbanisation, University of Oxford

\section{Acknowledgments:}

Panellists in the COP26 Climate Risk Summit session 'Cities infrastructure resilience: Global adaptation management best practice and lessons learned' on 30th September 2021 contributed insights and graphics: Cristina Argudo, C40 Cities; Matheus Ortega, C40 Cities; Dr Nam Nguyen, Director, Klinova; Dr Andy Kerr, EIT Climate-KIC UK\&I and Catherine Pearce, Sniffer. 
This technical report shares examples of climate risk interventions from different global cities, with the aim of understanding how city governments could embed adaptation management into their processes to strengthen climate resilience. Four city case studies are presented and their climate profile, associated climate hazards and key interventions selected to address these hazards, are reviewed. The findings are consolidated to provide recommendations on how to embed adaptation management more effectively into city systems and to share best practice, as we cannot look at adaptation in isolation. Adaptation management needs to be smarter, swifter and embedded within the wider city governance processes and systems. It requires an ongoing cycle of preparation, response, and revision at city level, and opportunities to share lessons learned between cities at the international level, too.

\section{GLOBAL CITY PROFILES AND INTERVENTIONS}

Climate hazards experienced within global cities are diverse and depend on the local context and environmental conditions - however they all affect people, assets and services across the globe. Each city faces different climate risks and has taken different approaches to addressing these: introducing new technologies; changing approaches to land use planning and policies; developing nature-based solutions and future-proofing infrastructure. Cities design and implement adaptation interventions that strengthen climate resilience and contribute towards long-term climate change outcomes at local level.

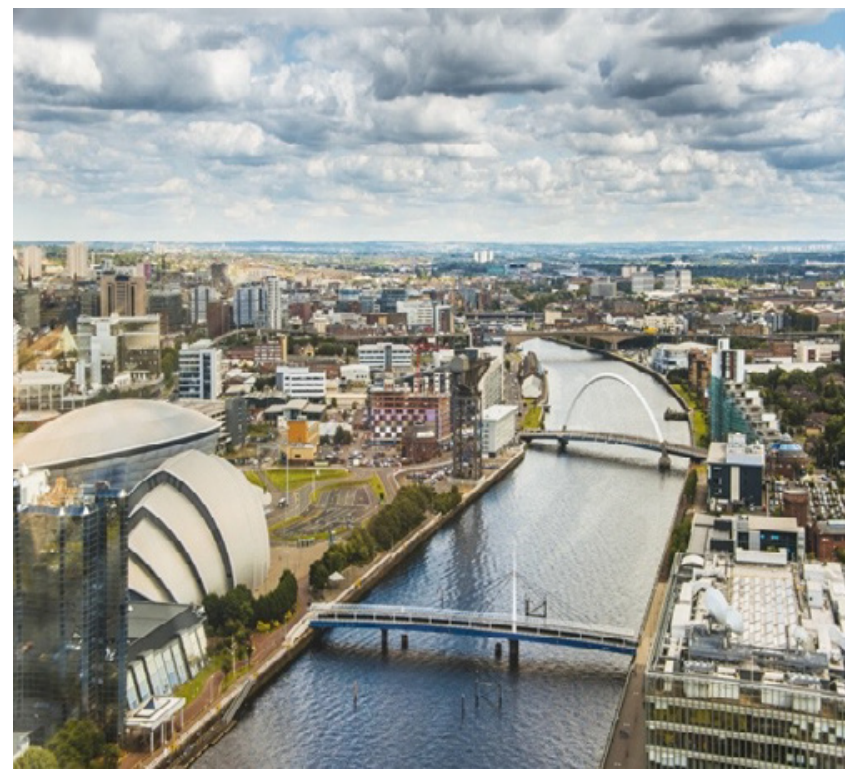

Glasgow, United Kingdom

of priority areas in the region have been identified as those where climate impacts could disproportionately affect vulnerable communities and/or have significant economic impact on the city's assets. Examples of priority areas are Clyde River corridor, coast, urban centres and Strategic Economic Investment areas (SEILs).

\section{A. GLASGOW, UNITED KINGDOM}

\section{Profile}

Glasgow City Region is a port city on the River Clyde in Scotland with a population of 1.8 million. It has a mix of urban (coastal) and rural areas all very well inter-connected. Observations show Glasgow City Region's temperatures and rainfall are increasing. The city is at risk of flooding if this trend continues (see graph below). The city's warmest years on record have all occurred since 1997. Climate impacts such as storms and extreme flooding will have effects across the region, and as a result, the city is exploring natural flood management approaches. A variety

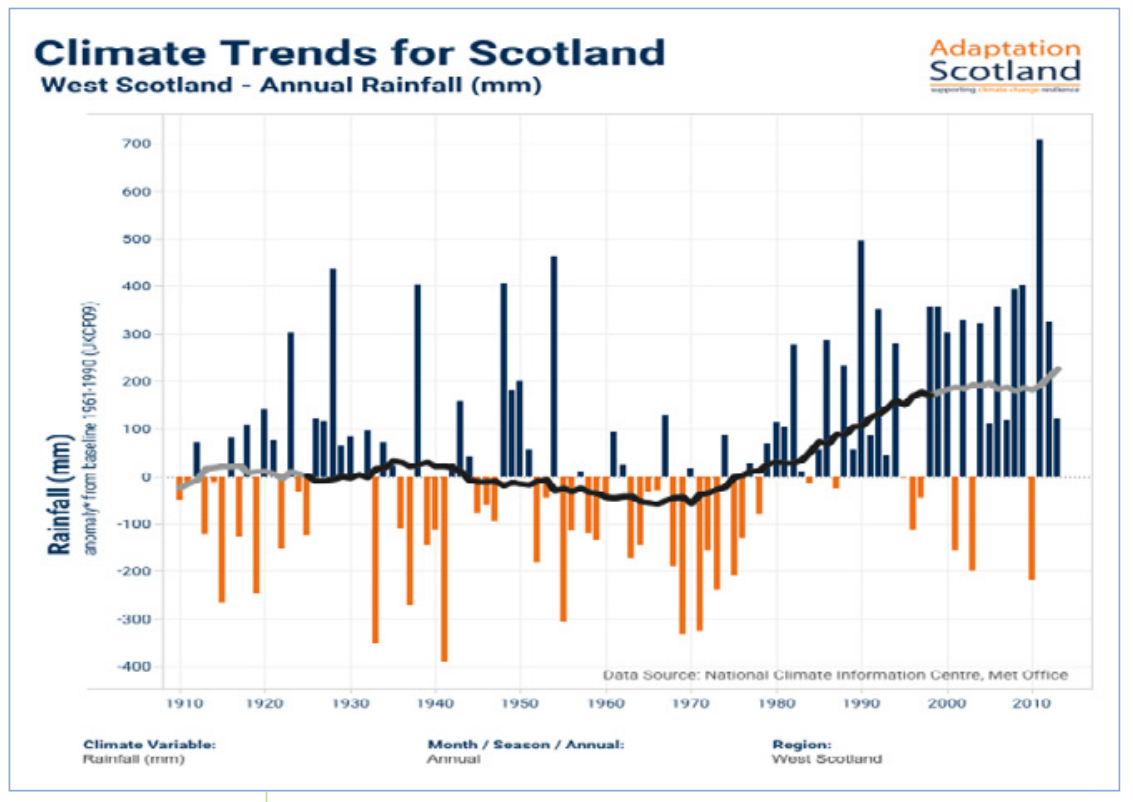

Figure 1. Climate trends in Scotland, Annual Rainfall, 2014. 


\section{Interventions}

The Glasgow City Region Climate Adaptation Strategy and Action Plan details key interventions and seeks to systematically transform the region's economy, society and natural environment to one which flourishes in our future climate within a decade. Flagship actions focus on creating an inclusive and collaborative approach to adaptation management and will require political and fiscal changes:

- Clyde Climate Forest - for canopy, connectivity and carbon absorption

- A new multi-hazard climate warning alert system

- Climate resilience integrated into regional supply chains and procurement

- Independent expert advisory committee on adaptation and climate resilience

- Local authorities in the region working together to build capabilities and deliver collaborative adaptation

- Private sector challenge for a climate resilient economy

- Regional investment pipeline and finance lab

- Regional transport resilience group.

\section{B. QUITO, ECUADOR}

\section{Profile}

Quito sits at the Andean foothills, surrounded by natural vegetation. It has a population of 2 million, a temperate climate, and a rainy season through the winter months (October - May). The city has experienced significant urban growth since the 1970s, which has resulted in rapid urban expansion. This has put pressure on key infrastructure and basic services (Vincenti et al. 2017). Quito has a diverse ecosystem, with different habitat types and local climates. In recent years, the city has experienced extreme heatwaves which have had an

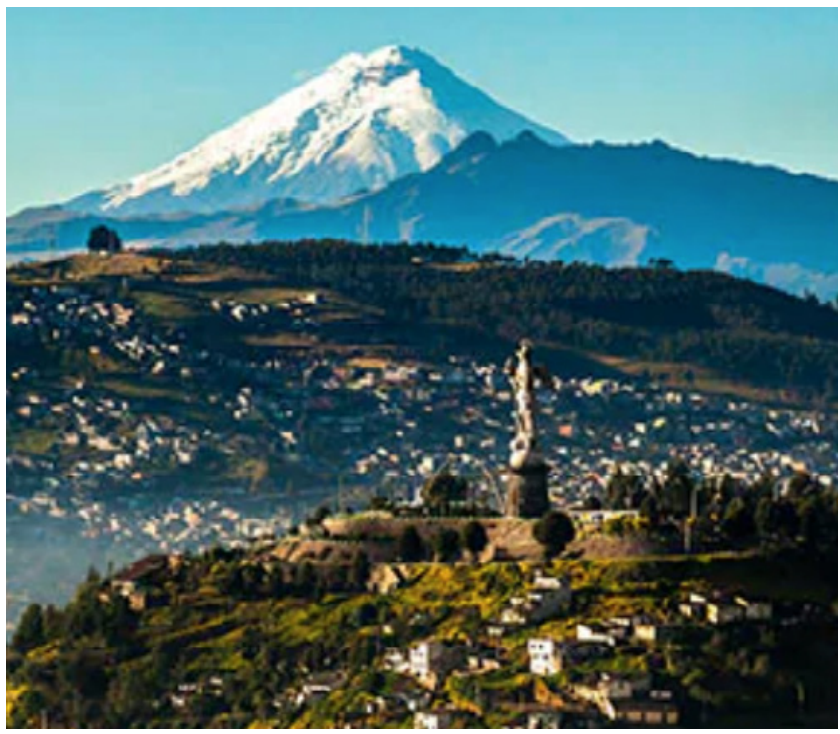

Quito, Ecuador impact on ecosystems, infrastructure, water availability and human health - both directly and indirectly.

The increase of temperatures above 25 degrees has put pressure on infrastructure as it has resulted in some movement of slopes around ravines occupied by lower income communities. The frequency of heatwaves is continuing. The city has taken a nature-based approach to addressing these climate hazards as it brings lower temperatures (creating cooler microclimates), increased biodiversity and conservation benefits.

\section{Interventions}

Quito has a history of developing action plans to address climate hazards and has sought to strengthen how the city generates and manages data, uses new technologies, communicates and approaches capacity-building. Interventions include:

- Implementation of nature-based solutions and green infrastructure for resilience

- Green urban network (5 green corridors, 12 parks and 183 ravines)

- Eco-efficiency tool to gather energy data from the built environment

- Increased urban vegetation and green space

- Increased urban agriculture
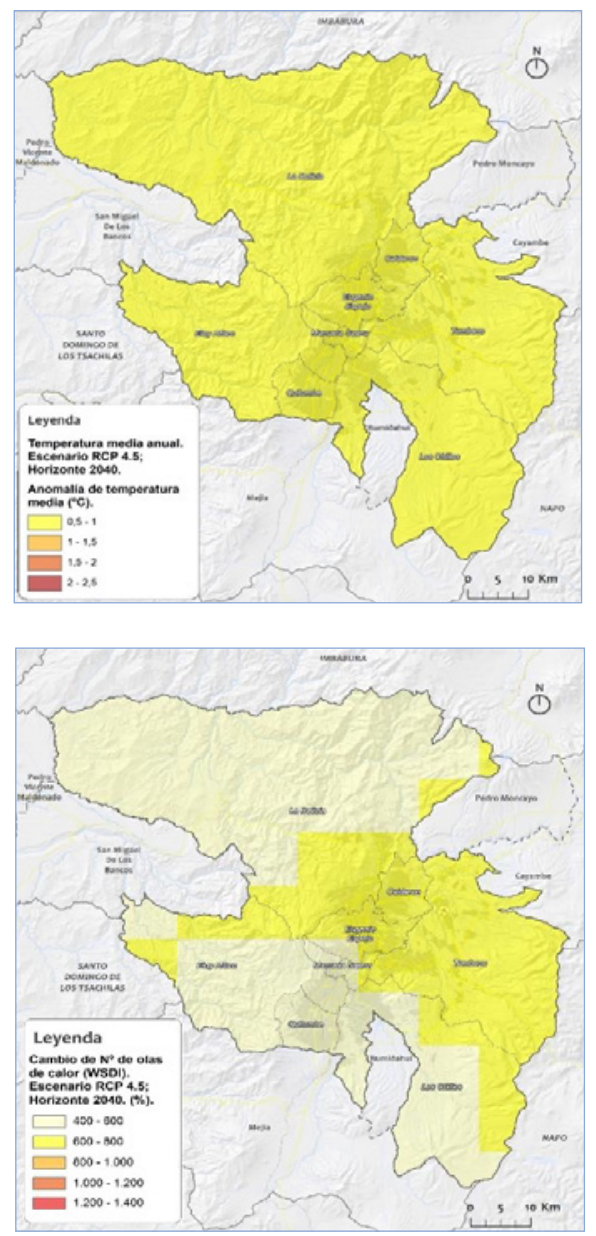

Figure 2. Average annual rainfall and precipitation in Quito. 


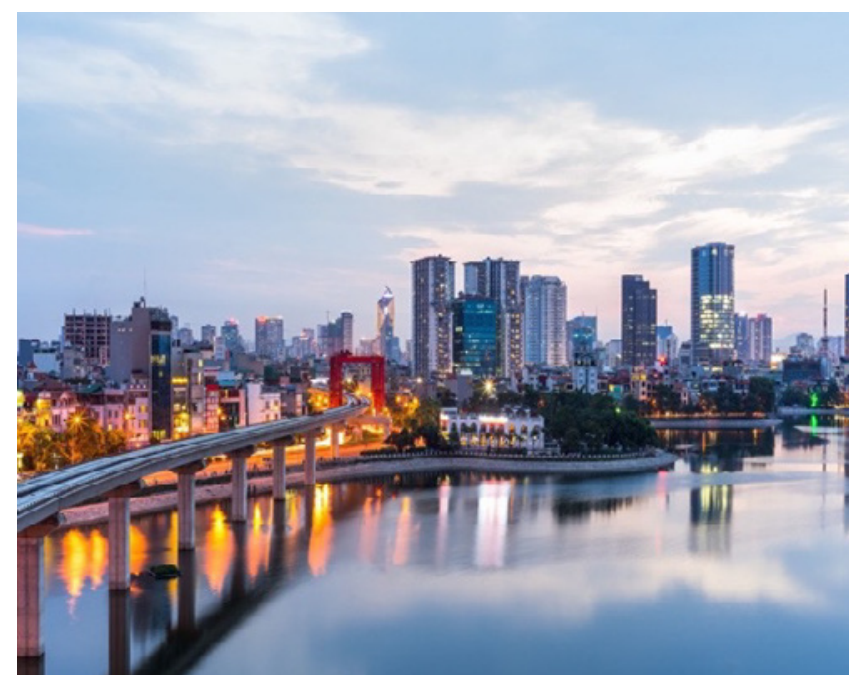

Hanoi, Vietnam

\section{HANOI, VIETNAM}

\section{Profile}

Hanoi is a large city (over 4.8 million people) located in the Red River delta in Northern Vietnam, with a sub-tropical climate. Over the past fifteen years, Hanoi has experienced climate extremes which resulted in higher temperatures and heavy rain spells. This has had a key impact on the frequency of forest fires and availability of fresh water. For example, in 2020, Northern Vietnam experienced the hottest heatwave in 49 years. There are variations in how these climate risks impact different parts of the city especially deprived areas.
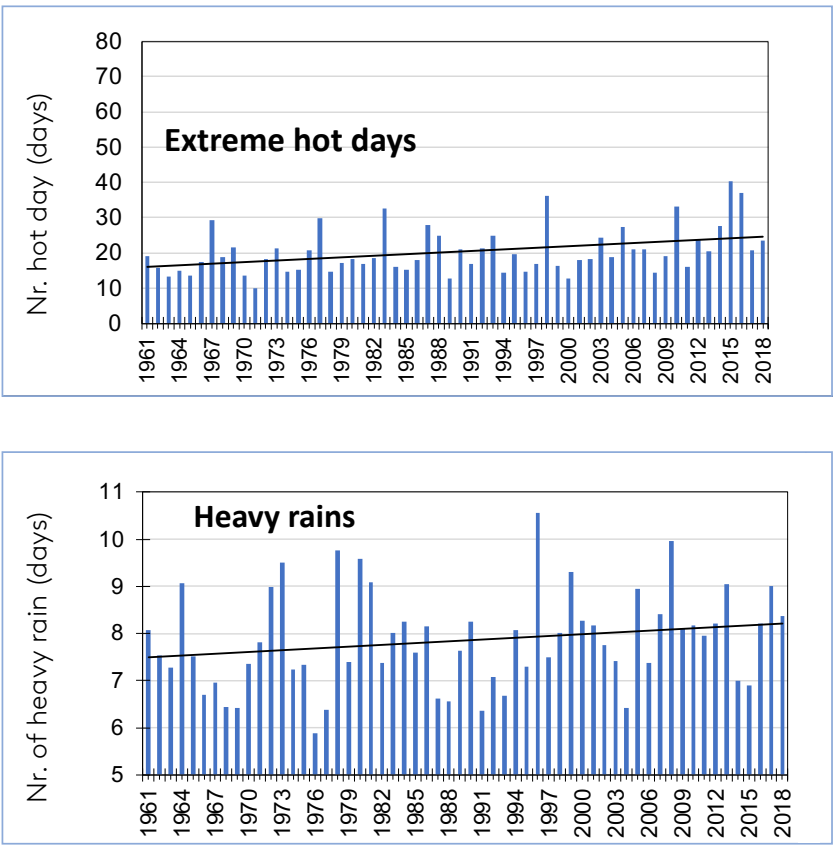

Figure 3. Number of extreme hot days and heavy rainfall days in Hanoi, Vietnam

\section{Interventions}

Hanoi is part of the C40 Cities Climate Leadership Group. The city conducted a detailed action, selection and prioritisation process with them in order to identify key interventions that would strengthen the resilience of critical infrastructure and services within the city:

- Develop an accessible, reliable and affordable public transport network

- Develop bicycle sharing model in urban areas

- Restrict the use of motorbikes in urban districts in line with the existing infrastructure and capacity of public passenger transport

- Upgrade and improve the drainage system and build the wastewater collection system

- Rehabilitate large and medium reservoirs

- Provide clean water system for districts without access to the city clean water system

- Increase greenery in urban areas

- Upgrade local medical stations to address climate risk emergencies

- Update forest fire prevention and fighting infrastructures in increasing drought conditions.

\section{SALVADOR, BRAZIL}

\section{Profile}

Salvador is a coastal Brazilian city with a tropical rainforest climate and a population of 3 million. The city has experienced flooding and landslides that disproportionately impact vulnerable communities within informal settlements on the outskirts of the city (Cirano and Lessa 2007). Over a third of the population live in informal housing and over $45 \%$ live in areas prone to extreme weather events (IBGE 2010). Although average annual precipitation is decreasing, precipitation overall is increasing, with more dramatic rainy seasons (March to May), resulting in more frequent climate hazards.

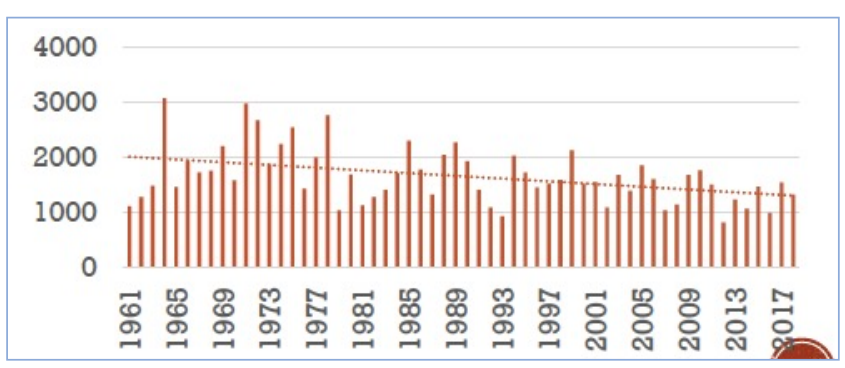

Figure 4. Total Annual Precipitation in Salvador, 1961-2018 


\section{Interventions}

In 2020, the city launched its first Climate Action Plan, with specific adaptation goals and actions based on the climate risk assessment. Salvador prioritised reducing spatial and social inequalities through their adaptation planning approach by introducing policies that re-locate communities living in areas prone to climate hazards, educate them on climate risk and develop climate resilient structures within the city.

- Conduct community training on climate change adaptation in $50 \%$ of high-risk areas served by Civil Protection and Defence Centres (2018)

- Reach $36 \mathrm{~m} 2$ of green space per capita for the whole city (2020 baseline 30m2)

- Initiate wastewater treatment and re-use

- Increase capacity of extreme weather event monitoring and early warning systems by $50 \%$ compared to 2018

- Promote the implementation of structural measures to reduce landslide risk by $30 \%$ in high-risk areas mapped by Codesal

- Reduce share of the population living in high-risk areas from $45-30 \%$ by 2049

- Publish strategy by 2032 to address sea-level rise by 2049

- Reduce outbreak of vector borne diseases by $30 \%$ in 2032 compared to 2018 rates.

\section{CLIMATE RESILIENCE TRENDS WITHIN CITIES Intervention trends}

Despite different climate hazards, risks and interventions experienced in cities around the world, each case study provides insight on key trends emerging within adaptation management. Common approaches include urban greening to reduce temperatures and improve health and well-being as well as enhancing local biodiversity. Green areas and sustainable urban drainage systems (SUDS) can also act as flood sponges to mitigate the impact of flash floods. Strengthening the resilience of critical services and infrastructure within a city was a theme that emerged from the intervention review. For example, improving connectivity and transportation systems, designing resilient drainage systems as well as water and waste-water system and improving the built environment to mitigate the likelihood of landslides. Other interventions focused on protecting at-risk groups within the city (e.g., populations with lower income or those located in areas prone to extreme climate events). Collaboration was a key theme emerging for the intervention review: many actions are aimed at encouraging cross-sectoral collaboration through the creation of advisory boards (e.g.,

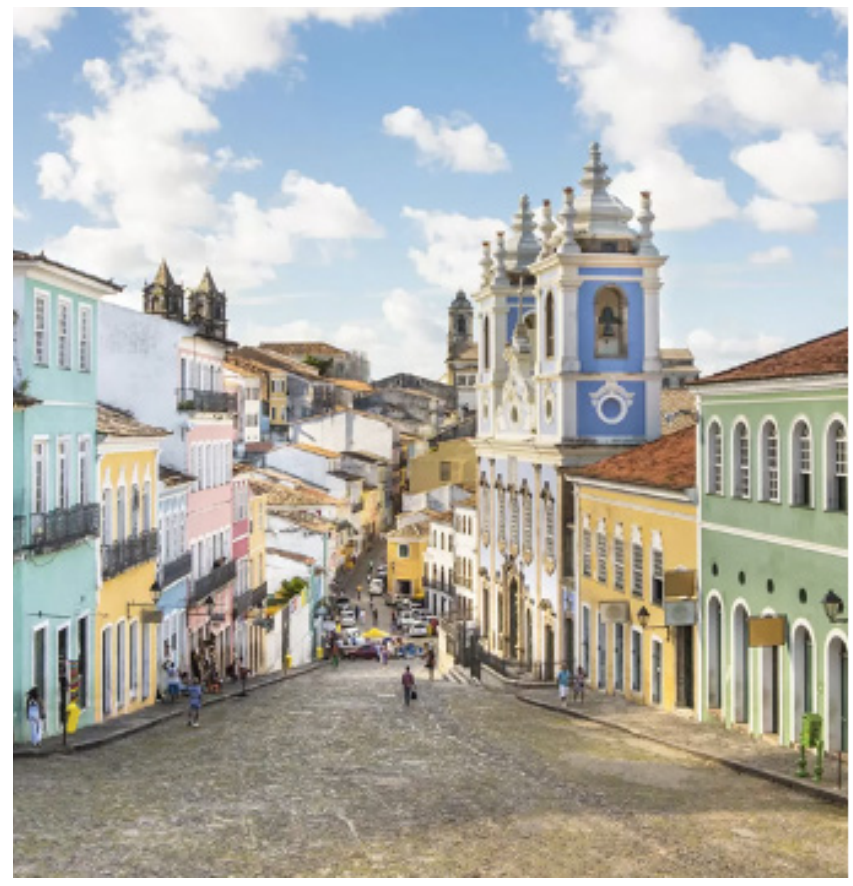

Salvador, Brazil

Glasgow) and training local communities to better understand risk (e.g., Salvador's training targets).

\section{Enabling interventions trends}

Although cities adopted different approaches - from strengthening service infrastructure to prioritising addressing social inequalities - the effective implementation of these interventions did require overcoming many barriers. The challenges identified from the case study interventions review include:

- Strengthening adaptation governance: Although many cities are making progress on climate resilience and adaptation management, many approaches focus on adapting to a specific range of climate hazards which impact specific sectors and/or groups of people unequally (E3G 2020). This is compounded by other challenges that municipalities face, such as a lack of data and in-house expertise, lack of finances and resources, or the ineffective governance of climate hazards. Adaptation decision-making often remains siloed within one municipal department, whereas the adaptation approach should be embedded within all municipal departments and in all governance processes and systems (Maria-Therese and Ece 2020). Key decisions are often taken after a climate event; however, earlier decision-making is needed to avoid risk well in advance. In addition, the term adaptation is often framed too narrowly within decision-making bodies and institutions (the current focus is on economic rather than social vulnerability). Rather than a narrow perception of 'adaptation' focused on specific climate risks, cities need cross-sectoral collaboration to effectively address all climate hazards within urban areas. 


\section{- Ensuring stakeholder engagement and} collaboration: Adaptation management is a crosssectoral issue of interest to a wide range of local stakeholders within cities (Gramberger et al 2015). Stakeholder engagement and participation can greatly support adaptation action and acquire buyin for local plans in order to address disparity across the city. Understanding key stakeholders within the city and what their interests, influence and positions are can strengthen the adaptation planning process. Collaborating with sectoral authorities, interest groups, NGOs or representatives from the private sector is required throughout the entire process - from light touch engagement (e.g., informing of plans) to consultation and participatory involvement. For example, co-creating adaptation actions or local projects that ensure the adaptation approach taken is bottom-up and that the local perspectives of climate hazards in affected areas are properly understood and addressed within local planning. Buy-in from local stakeholders is critical to address climate impact within cities.

\section{- Improving climate risk data and metrics:}

Changing the way cities gather data and measure climate risk is essential to address climate hazards. Cities are increasingly turning to digital technology and artificial intelligence to collect data and analyse climate data (Sarker 2020; Ford et al 2016). They often lack complete data to understand how climate risks affect the population, tending to base the analysis on economic data. However, by taking this approach they exclude a substantial percentage of the population who are often most adversely impacted by climate hazards. City officials are now working to integrate new climate data into existing systems, gather local data to inform communitylevel decisions and integrate social science data into resiliency planning. Effective use of data provide an opportunity for cities to capitalize on better and cheaper data collection methods and analytical tools and use them to minimise the impact of climate hazards, particularly in global south cities. In addition, cities should move away from purely economic metrics within adaptation management and consider deprivation and social equity challenges as well.

\section{CONCLUSION}

Cities are at the forefront of the debate on how to address climate change: they provide the best opportunity to reduce carbon emissions and strengthen climate risk. In recent years, climate adaptation has become a global challenge, with cities affected by different hazards, now identifying a range of interventions to mitigate or reduce the impact of these risks. This technical report brings together four global case studies; it demonstrates some of the different challenges, approaches and interventions taken to address the impact of climate change. The comparison highlighted the similarities in the types of interventions, which suggests that best practice approaches have been identified. More importantly, they show the importance of enabling mechanisms - the supportive interventions or actions needed to be addressed to implement key interventions. These enabling mechanisms, governance, collaboration and data--, are central in strengthening local climate resilience and highlight the need for international cooperation. More effective multi-level governance, collaborating with citizens, public and private stakeholders, can draw on expertise and local knowledge to address complex hazards; data sharing on a global scale could accelerate the implementation of tried and tested solutions. Innovative approaches, experimentation, best practice and sharing lessons learned between cities (as well as acknowledging what has not worked) will be key for improving urban resilience and mitigating the impact of climate change. Climate adaptation is an increasingly global challenge. Robust solutions and sharing lessons are essential to future-proof our cities. 


\section{REFERENCES}

1. Cirano, M. and Lessa, G.C., (2007) Oceanographic characteristics of Baía de Todos os Santos, Brazil. Revista brasileira de geofísica, 25, pp.363-387.

2. E3G (2020) Developments in climate resilience governance in the EU: A review of the research and emerging recommendations, Discussion paper, September 2020, available here.

3. Gramberger, M., Zellmer, K., Kok, K. and Metzger, M.J., (2015) Stakeholder integrated research (STIR): a new approach tested in climate change adaptation research. Climatic change, 128(3), pp.201-214.

4. Farhad, N. (2021) Focused adaptation: A strategic approach to climate adaptation in cities, C40 Cities and McKinsey Sustainability, available here, accessed 20211024.

5. Ford, J.D., Tilleard, S.E., Berrang-Ford, L., Araos, M., Biesbroek, R., Lesnikowski, A.C., MacDonald, G.K., Hsu, A., Chen, C. and Bizikova, L., 2016. Opinion: Big data has big potential for applications to climate change adaptation. Proceedings of the National Academy of Sciences, 113(39), pp.10729-10732.

6. Chu, E., Brown, A., Michael, K., Du, J., Lwasa, S. and Mahendra, A., (2019) Unlocking the potential for transformative climate adaptation in cities. Background Paper prepared for the Global Commission on Adaptation, World Resources Institute, Washington, DC and Rotterdam.

7. Brazilian Institute of Geography and Statistics, IBGE (2010) Deprivation census data Salvador, available here.

8. Hunt, A. and Watkiss, P., 2011. Climate change impacts and adaptation in cities: a review of the literature.

Climatic change, 104(1), pp.13-49.
9. Maria, D.L., Maria-Therese, G. and Ece, K. (2020)

Global adaptation governance: Explaining the governance responses of international organizations to new issue linkages. Environmental Science \& Policy, 114, pp.204-215.

10. Paris Agreement (2015) December. Paris agreement. In Report of the Conference of the Parties to the United Nations Framework Convention on Climate Change (21st Session, 2015: Paris, Vol. 4, pp. 2017.

11. Sarker, M.N.I., Yang, B., Lv, Y., Huq, M.E. and Kamruzzaman, M.M., (2020) Climate change adaptation and resilience through big data. Int J Adv Comput Sci Appl, 11(3), pp.533-539.

12. Serrano Vincenti, S., Ruiz, J.C. and Bersosa, F., (2017) Heavy rainfall and temperature proyections in a climate change scenario over Quito, Ecuador. LA GRANJA. Revista de Ciencias de la Vida, 25(1), pp.16-32.

Figure 1. Adaptation Scotland (2014) Climate trends in Scotland, Annual Rainfall, available here.

Figure 2. IDOM, C40 and the City of Quito (2020) Quito's Climate Risk Assessment, Average Annual rainfall and precipitation in Quito graph.

Figure 3. Klinova (2020) Hanoi climate hazards, Number of extreme hot days and heavy rainfall days in Hanoi, Vietnam graph.

Figure 4. Salvador's Civil Defence (CODESAL) (2019) Total Annual Precipitation in Salvador, 1961-2018, graph.

\section{THE COP26 UNIVERSITIES NETWORK}

The COP26 Universities Network Climate Risk Notes are an outcome of the Climate Risk Summit. The Summit aimed to bring key information on the risks of climate change and their communication to decision-makers to the attention of a wider audience in advance of COP26. The Climate Risk Notes crystallise and expand on the learnings from the Summit. The Climate Risk Notes series is published in association with the UK COP26 Universities Network, however all opinions are those of the named authors rather than those of the network as a whole.

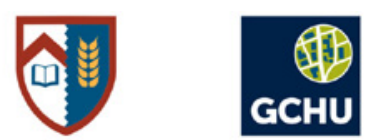

Kellogg College University of Oxford

\section{HOW TO CITE THIS PAPER}

Maxwell, K. (2021). Climate resilience interventions within global cities: how are cities addressing climate hazards and what's missing? COP26 Universities Network Climate Risk Note. 